\title{
Perineural steroids for trauma and compression-related peripheral neuropathic pain: a systematic review and meta-analysis
}

\section{Infiltrations périnerveuses de stéroïdes pour la douleur neuropathique périphérique d'origine traumatique ou compressive: une revue systématique de la littérature et méta-analyse}

\author{
Anuj Bhatia, MD · David Flamer, MD • \\ Prakesh S. Shah, MD \\ Received: 27 November 2014/ Accepted: 25 February 2015/Published online: 6 March 2015 \\ (C) Canadian Anesthesiologists' Society 2015
}

\begin{abstract}
Purpose Perineural steroids are often used to treat chronic peripheral neuropathic pain (NP) secondary to trauma or compression. Nevertheless, when compared with local anesthetics (LA) or conventional medical management (CMM), their efficacy and safety in patients with trauma or compression-related neuropathic pain syndromes is unclear. The purpose of this systematic review and meta-analysis was to determine the efficacy and
\end{abstract}

This manuscript was screened for plagiarism using http:// smallseotools.com/plagiarism-checker/.

Author contributions Anиj Bhatia wrote the manuscript. Anиj Bhatia and David Flamer participated in the acquisition of data. Anuj Bhatia, David Flamer, and Prakesh S. Shah helped design and conduct the study, and they participated in the conception of the review, the analysis and interpretation of data, and drafting the article.

Electronic supplementary material The online version of this article (doi:10.1007/s12630-015-0356-5) contains supplementary material, which is available to authorized users.

\footnotetext{
A. Bhatia, MD ( $\square)$

Department of Anesthesia and Pain Management, and Institute of Health Policy Management and Evaluation, University of Toronto, Toronto, ON, Canada

e-mail: anuj.bhatia@uhn.ca
}

\section{A. Bhatia, MD}

Department of Anesthesia and Pain Management, University Health Network-Toronto Western Hospital, McL 2-415, 399 Bathurst Street, Toronto, ON M5T 2S8, Canada safety of perineural steroids in compression or traumarelated NP after one to three months of injection.

Source We reviewed randomized controlled trials from MEDLINE ${ }^{\circledR}$, EMBASE ${ }^{T M}$, Cochrane central register of controlled trials, Cochrane database of systematic reviews, and Google Scholar (first 200 hits) up to April 2014 that compared perineural injections of steroids with LA or CMM in adult patients with trauma or compression-related chronic peripheral NP. A meta-analysis was performed on the data on pain scores measured at one to three months after the interventions. Quality of evidence was classified using the GRADE system. Two authors independently reviewed all identified titles and abstracts for eligibility. Principal findings Five trials comprising 353 patients (177 in the steroid group and 176 in the comparator groups) were included. At one to three months after the interventions, patients who received perineural steroids reported lower pain scores than those who received LA or CMM (mean difference: -1.31 points on a 0-10 numerical rating scale for pain; $95 \%$ confidence interval: -2.50 to -0.13; quality of evidence: low; $I^{2}=89 \%$ ). None of the studies reported any significant adverse effects.

\section{Flamer, MD}

Department of Anesthesiology and Pain Management, University of Toronto, University Health Network-Toronto Western Hospital, McL 2-405, 399 Bathurst Street, Toronto, ON M5T 2S8, Canada

\section{P. S. Shah, MD}

Departments of Paediatrics, Mount Sinai Hospital; Institute of Health Policy Management and Evaluation, University of Toronto, Toronto, ON, Canada 
Conclusions Perineural steroids may provide analgesic efficacy for one to three months in patients with chronic peripheral NP of traumatic or compressive origin; however, the strength of this recommendation is weak. Well-designed large randomized studies are required.

\section{Résumé}

Objectif Les infiltrations périnerveuses de stéroüdes sont souvent utilisées pour le traitement de la douleur neuropathique périphérique chronique secondaire à un traumatisme ou une compression. Néanmoins, quand on les compare aux anesthésiques locaux (AL) ou à la prise en charge médicale conventionnelle (PCM), leur efficacité et sécurité chez les patients souffrant de syndromes neuropathiques douloureux secondaires à un traumatisme ou à une compression ne sont pas claires. Les objectifs de cette étude systématique et méta-analyse étaient de déterminer l'efficacité et l'innocuité des infiltrations périnerveuses de stérö̈des dans les neuropathies périphériques liées à une compression ou à un traumatisme, entre un et trois mois après l'injection.

Source Nous avons analysé les études randomisées et contrôlées dans MEDLINE ${ }^{\circledR}, E_{1}$ BASE ${ }^{T M}$, le registre central Cochrane des essais contrôlés, la base de données Cochrane des analyses systématiques et dans Google Scholar (les 200 premiers impacts) jusqu'en avril 2014 qui comparaient les infiltrations périnerveuses de stéroïdes à l'AL ou à la PCM chez des patients adultes souffrant de NP périphérique chronique secondaire à un traumatisme ou une compression. Une méta-analyse a été réalisée sur les données de scores de douleur mesurés entre un et trois mois après les interventions. La qualité des preuves a été classée en utilisant le système GRADE. Deux auteurs ont revu de façon indépendante tous les titres et résumés identifiés pour évaluer leur admissibilité.

Constatations principales Cinq essais totalisant 353 patients (177 patients dans le groupe stéroïdes et 176 dans le groupe comparateur) ont été inclus. Un à 3 mois après les interventions, les patients ayant reçu une infiltration périnerveuse de stéroïdes ont déclaré des scores de douleur inférieurs à ceux qui avaient reçu une AL ou une PCM (différence moyenne: -1,31 point sur une échelle numérique [0 à 10] d'évaluation de la douleur; intervalle de confiance à $95 \%$ : -2,50 à 0,13; qualité de la preuve: faible; $\left.I^{2}=89 \%\right)$. Aucune de ces études n'a signalé d'effets indésirables significatifs.

Conclusions Les infiltrations périnerveuses de stérö̈des peuvent avoir une efficacité analgésique pendant un à trois mois chez des patients atteints de NP périphérique chronique d'origine traumatique ou compressive; toutefois, la force de cette recommandation est faible. De grandes études randomisées bien conçues sont nécessaires.

Neuropathic pain (NP) affects about $7 \%$ of the population and $>20 \%$ of patients with chronic pain have neuropathic characteristics. ${ }^{1}$ Peripheral NP, defined as pain caused by a lesion or disease affecting the peripheral somatosensory nervous system, ${ }^{2,3}$ is often severely debilitating, and it is largely resistant to treatment. ${ }^{4,5}$ Though multiple treatment modalities have been proposed for this type of pain, a significant number of patients have inadequate pain relief and/or experience adverse effects (e.g., cognitive and gastrointestinal impairment) from conventional medical management (CMM). Only one in every three patients who receive these treatments experiences analgesic benefit. ${ }^{5}$ Unrelieved NP is also associated with significant anxiety, depression, and worsening of quality of life. ${ }^{6,7}$

Neuropathic pain has multiple etiologies, but entrapment/compression in tissue planes and trauma are important causes ${ }^{8}$ that often result in chronic pain (i.e., pain persisting for more than three months) of moderate-tosevere intensity (i.e., $>3$ on a $0-10$ numerical rating scale [NRS] for pain). The fibres of damaged nerves display enhanced neuronal activity from injured primary afferents, which leads to the development of NP. ${ }^{9}$ Local anesthetics (LA) are often injected around nerves to provide perioperative analgesia, ${ }^{10}$ but there is a lack of consensus on the role of perineural administration of steroids in the management of NP. ${ }^{11}$

Nerve injury has been shown to activate secretion of inflammatory mediators and increase ectopic discharge from the injured nerve, ${ }^{4}$ thereby contributing to the development of NP. ${ }^{12,13}$ Application of steroids to injured nerve fibres suppresses both of these mechanisms, ${ }^{14}$ alleviates edema, and can provide analgesia. Perineural injections of steroids have been used to treat pain from Morton's neuroma ${ }^{15}$ and from post-traumatic and/or compression neuropathies. ${ }^{16,17}$ Nevertheless, evaluation of the available evidence is hampered by different methodologies and conflicting conclusions in individual papers. Studies on the efficacy of perineural steroids for NP have used small population sizes, which inflates the risk of type II statistical error. Therefore, the primary objective of this systematic review and meta-analysis was to determine the efficacy and safety of perineural steroids in compression or trauma-related NP after one to three months of injection. Secondary objectives were to assess the impact of this intervention on pain-associated domains (anxiety, depression, patient satisfaction) and safety. 


\section{Methods}

This systematic review was conducted according to the current recommendations of the Cochrane Collaboration, ${ }^{18}$ and it is reported following the PRISMA guidelines. ${ }^{19}$

Search strategy and study selection

We conducted a search of the literature until April 24, 2014. The following three databases were searched: EMBASE ${ }^{\mathrm{TM}}$, 1947-April 24, 2014; MEDLINE $^{\circledR}$, 1946-April week 3, 2014; and MEDLINE In-Process \& Other Non-Indexed Citations, April 24, 2014 (all using the OvidSP platform). For EMBASE and MEDLINE, controlled vocabulary terms (EMBASE - Emtree; MEDLINE - MeSH) and text word searching were conducted for each of the following search segments: peripheral pain + neuropathic pain (peripheral) + steroids + injections. Each search was limited to English language and human subjects. We applied a highly sensitive search strategy to identify studies. $^{20}$ Details of our search strategy are provided in the Appendix.

We also searched the Cochrane central register of controlled trials, Cochrane database of systematic reviews, Google Scholar (first 200 hits), and proceedings of the annual meetings of anesthesiology and pain societies (American Society of Anesthesiologists, European Society of Anaesthesiology, International Association for the Study of Pain, American Society of Regional Anesthesia and Pain Medicine, European Society of Regional Anaesthesia \& Pain Therapy, and World Institute of Pain) in the last two years. We also searched for randomized controlled trials (RCTs) in the metaRegister of Controlled Trials (includes ClinicalTrials.gov). Only studies in English were included because most scales for diagnosing and measuring NP have been validated solely in this language.

We completed the search by reviewing the bibliographies of every selected article for possible additional articles that had not been retrieved by the search. Two authors (A.B. and D.F.) independently evaluated titles, abstracts, and full texts according to the inclusion criteria. All instances of discord were discussed between the investigators to reach a consensus.

\section{Participants}

Inclusion criteria were: (i) age $\geq 18 \mathrm{yr}$; (ii) chronic $(\geq$ 3 months) peripheral (including peripheral part of cranial nerves) NP of moderate-to-severe intensity ( $>3$ on a $0-10$ numerical rating scale for pain) diagnosed on the basis of symptoms, signs, or validated scales for NP or a combination of the three; (iii) etiology of peripheral NP was compression and/or trauma related; and (iv) received injections in the vicinity of the neural pathology using anatomic landmarks, nerve stimulation, or ultrasound guidance.

Intervention and comparator

We included studies in which participants received at least one injection of perineural steroids for NP compared with no injection (i.e., CMM) or LA or placebo (saline) injections. Conventional medical management included medications (antidepressants, anticonvulsants, antiinflammatories, opioids) and other modalities (e.g., physiotherapy) recommended for treatment of NP. Steroids considered for this review included methylprednisolone, dexamethasone, betamethasone, triamcinolone, or any other intermediate-to-long-acting steroids. We did not impose restrictions on dose of steroids or number of injections. In studies with additional cohorts comparing combinations of perineural steroids with LA, we attempted to extract the data for the comparison between steroids and LA. We excluded studies of other perineural adjuvants (e.g., botulinum toxin, clonidine, cytokine antagonists) from our analysis and studies using topical application of steroids. We also excluded trials on neuromodulation (central or peripheral), cryotherapy, radiofrequency (pulsed or ablation), or other surgical modalities (nerve release or neurectomy) for the treatment of peripheral NP.

\section{Outcomes}

The primary outcome was pain at one to three months after the intervention expressed on a NRS $(0=$ no pain to $10=$ worst possible pain). Intensity scores reported on a visual analogue scale (VAS; $0=$ no pain to $100=$ worst possible pain) were transformed to a 0-10 NRS. The secondary outcomes considered at one to three months after the intervention were: anxiety, depression, quality of life (all measured on validated scales, e.g., SF-36 ${ }^{\circledR}$, EQ$5 \mathrm{D}^{\mathrm{TM}}$ ), overall patient satisfaction, and number of patients with steroid-related adverse events (infection, hyperglycemia, osteoporosis or fractures, psychosis, muscle wasting, dermatological signs) or complications related to the injection (hematoma formation, injury to or penetration of anatomical structures in the vicinity of the nerve).

\section{Risk of bias assessment}

The risk of bias among included studies was evaluated using the Cochrane Collaboration tool for assessing risk of bias. ${ }^{18}$ This tool assesses bias in the following domains: generation of allocation sequence, allocation concealment, 
blinding of investigators and participants, blinding of outcome assessors, and incomplete outcome data. Each item was classified as low, unclear, or high risk of bias. A decision to classify "overall bias" as low/unclear/high was made depending on the trend of the majority of the domains. We also intended to use a funnel plot and an assessment of its asymmetry to assess publication biases (citation bias, selective outcome reporting) if a sufficient number of studies were available for meta-analysis.

\section{Data extraction}

The reference data, populations, and outcomes were then extracted from the articles into pre-specified tables. The two authors (A.B. and D.F.) used a standardized data extraction procedure. The data collection form was pilottested prior to its use. We extracted information on the studies' general characteristics (including design, number of arms, and primary outcome), participants (population characteristics, sample size, and etiology of NP), and experimental intervention (type of steroid, doses, and administration regime). Dichotomous outcomes were extracted as the presence or absence of a therapeutic or adverse effect. For continuous data, we extracted means and standard deviations (SDs). If not reported, the SDs were obtained from confidence intervals (CI) or $P$ values that related to the differences between means in the two groups. $^{21}$

\section{Data synthesis and analysis}

We expected heterogeneity (because of the diverse populations and doses of steroids included), and therefore, we used DerSimonian and Laird random effects meta-analysis models. ${ }^{22}$ Heterogeneity was assessed with the Q test, and the Higgins $I^{2}$ statistic was used to quantify heterogeneity $\left(I^{2}>50 \%\right.$ indicates substantial heterogeneity). The estimated mean effect of each study was calculated with the respective $95 \% \mathrm{CI}$, and the pooled effect was then assessed. An investigation of the sources of heterogeneity was based on an analysis of prespecified subgroups. The definition of the subgroups included: type of nerve, level of steroid dose (high vs low; low was defined as a methylprednisolone dose of up to $40 \mathrm{mg}$ or an equipotent dose of another steroid), and quality of trials. Subgroup analysis for type of nerve was performed because median nerve compression (carpal tunnel syndrome) tends to cause milder symptoms of NP (usually dysesthesia $v s$ allodynia or hyperalgesia). ${ }^{23}$ Thus, patients with compression of this nerve may have some unique characteristics that are different when compared with patients with neuropathic syndromes due to trauma or compression of other peripheral nerves. After inspection of results, we performed a post hoc subgroup analysis to compare the outcomes of trials in which the primary outcome was reported early (within the first two months of intervention) $v s$ late (at three months after the intervention), because the efficacy of steroids tends to wane with time. We also decided to perform a post hoc sensitivity analysis on the primary outcome measure by evaluating the impact of removing one trial with a strongly positive result in favour of steroids. All statistical analyses were performed with Review Manager (RevMan version 5.2.5; The Nordic Cochrane Centre, The Cochrane Collaboration, Copenhagen, Denmark).

\section{Quality of evidence}

The quality of evidence for the primary outcome was assessed with GRADE (Grading of Recommendations, Assessment, Development and Evaluation) methodology. ${ }^{24}$ Quality of evidence was classified as high, moderate, low, or very low for each outcome based on risk of bias, inconsistency, indirectness, imprecision, and other considerations (publication bias). A summary table was constructed with GRADEpro version 3.6 (http://www.guidelinedevelopment. org/; Evidence Prime Inc., Hamilton, ON, Canada).

\section{Results}

Search results

The search results and study selection flow chart are reported in Fig. 1. Five RCTs (published from 2011-2013) comprised of 353 patients (177 in the steroid groups and 176 in the comparator groups) were included for systematic review and meta-analysis (Fig. 1). ${ }^{25-29}$

Trial, participants, and intervention characteristics (Table 1)

All of the studies in the steroid groups involved a single injection of steroid. The median (range) target sample size was 88 (30-131) patients. The studies investigated patients receiving perineural steroids for NP secondary to compression or trauma of various peripheral nerves (common peroneal, suprascapular, popliteal, sciatic, thoracic paravertebral, and femoral nerves), ${ }^{25}$ median nerve at the carpal tunnel, ${ }^{26,29}$ the ninth (glossopharyngeal) cranial nerve, ${ }^{28}$ and interdigital nerves in the foot (Morton's neuroma). ${ }^{27} \mathrm{~A}$ validated scale for diagnosing NP was used in only one study (i.e., the Leeds Assessment of Neuropathic Symptoms and Signs LANSS), ${ }^{25}$ and all other studies enrolled participants only on the basis of neuropathic signs and symptoms. 


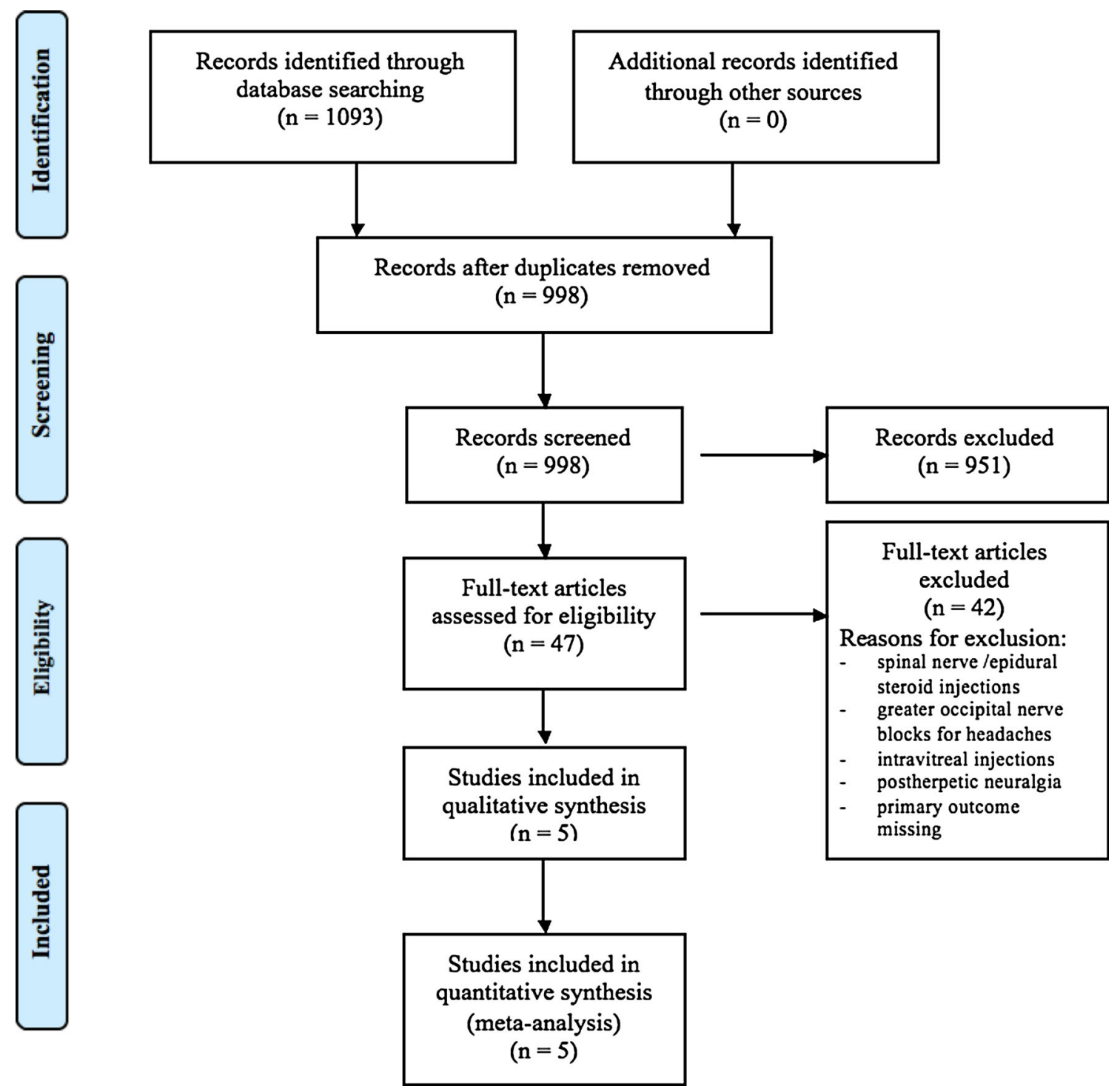

Fig. 1 PRISMA (Preferred Reporting Items for Systematic Reviews and Meta-Analyses) flow chart for studies included in the review

The two studies involving compression of median nerves also included electrophysiological criteria to diagnose neuropathy. ${ }^{26,29}$

Three studies had two groups for direct comparison of steroids with LA or CMM. ${ }^{25,27,28}$ The other two studies (both on median nerve compression) had three groups. ${ }^{26,29}$ In one of these two studies, steroids with and without LA were compared with $\mathrm{LA}^{29}$; whereas, in the other study, steroids were compared with LA in one group and with placebo in another group. ${ }^{26}$ The perineural steroids used in the studies were methylprednisolone $\left(40 \mathrm{mg}^{27}\right.$ or $80 \mathrm{mg})^{25,28}$ and triamcinolone $(40 \mathrm{mg})^{26,29}$ Local anesthetics used in the comparator groups were lidocaine $(0.5 \% \text { or } 2 \%)^{25,27}$ or procaine $(1 \%) .^{26,29}$ Prior to perineural injection, the nerves were located using stimulation, ${ }^{25}$ ultrasound, ${ }^{27}$ or anatomic landmarks. ${ }^{26,28,29}$ The primary or secondary outcome in all five studies was the mean pain score using NRS or VAS measured at one to three months after the interventions. (Table 1) Other measured outcomes included LANSS scores and mean daily analgesic intake, ${ }^{25}$ electrophysiological studies, ${ }^{26,29}$ syndrome-specific scores, ${ }^{26,27,29}$ and brief pain inventory scores. ${ }^{28}$ Adverse effects were reported anecdotally in only two studies. ${ }^{27,28}$

Risk of bias assessment of the included studies (Fig. 2)

Two trials were classified as being at low risk of bias, ${ }^{25,27}$ and the other three were at a high risk of bias. ${ }^{26,28,29}$ In two of the three trials deemed to have a high risk of bias, the procedure for randomization was not adequately described. ${ }^{26,29}$ All three trials did not confirm allocation concealment or blinding, and the reporting of outcome data was incomplete. 


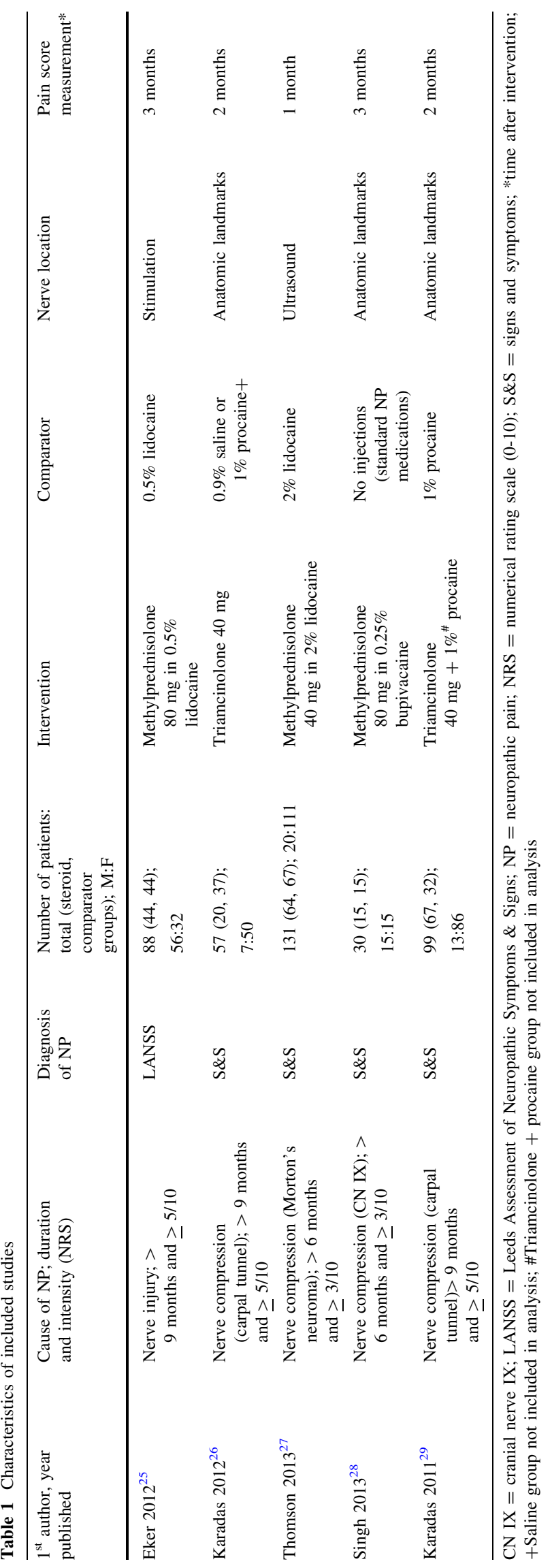

Primary outcome

Pain scores for all trials at one to three months after intervention (Fig. 3)

All five trials reported mean pain scores at one to three months after perineural injection of steroids or LA/CMM. Two trials had three groups each, and groups with a saline injection $^{26}$ or a combination of LA and steroids ${ }^{29}$ were excluded from analysis to avoid "double counting". Data from 353 patients were combined for meta-analysis. (Fig. 3) There was a significant reduction in mean pain scores in patients receiving steroids compared with patients receiving $\mathrm{LA} / \mathrm{CMM}(-1.31$ points; $95 \% \mathrm{CI}:-2.50$ to $\left.-0.13 ; P=0.03, I^{2}=89 \%\right)$.

The difference in mean pain scores between the two groups represents approximately a $25 \%$ reduction from the mean baseline pain scores (5-6 on a 0-10 NRS). Table 2 shows the change in mean pain scores from baseline for both the steroid and LA/CMM groups: the range for the steroid groups was a $29-75 \%$ reduction compared with a $16-36 \%$ reduction for the LA/CMM groups. Larger

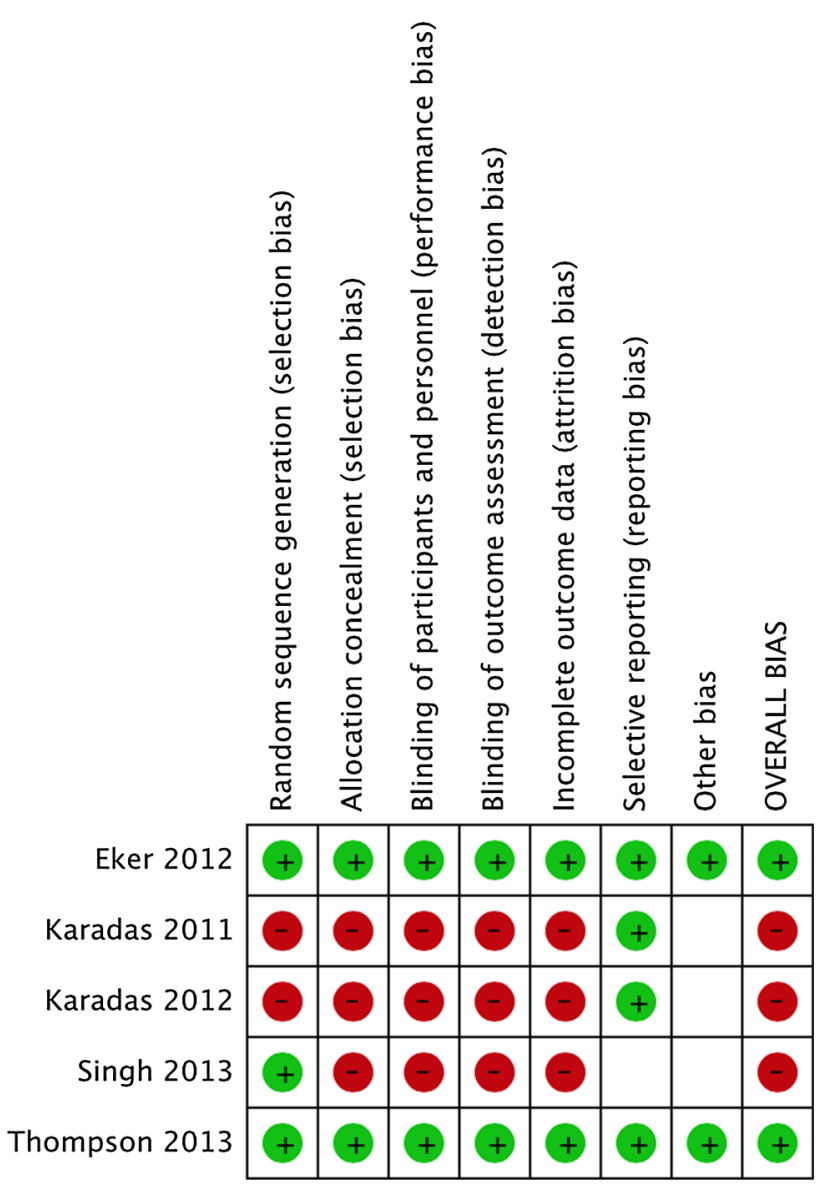

Fig. 2 Summary of risk of bias assessment (green = low risk; red $=$ high risk; blank $=$ unclear) 
reductions in pain scores were reported in trials involving use of higher doses of steroids (methylprednisolone $80 \mathrm{mg})^{25,28}$ compared with trials using lower doses (methylprednisolone or triamcinolone $40 \mathrm{mg})^{26,27,29}$; however, none of these studies compared different doses of steroids or different steroids.

\section{Pain scores at one to three months after intervention for median nerve compression trials (Table 3, Fig. 4)}

We performed a meta-analysis of trials that enrolled only patients with median nerve compression. ${ }^{26,29}$ Both trials included in this analysis were homogeneous. Though there was significant reduction in mean pain scores in patients receiving steroids compared with those receiving LA ( -0.86 points; $95 \% \mathrm{CI}:-1.49$ to $-0.23 ; P=0.03$; $\left.I^{2}=0 \%\right)$, the reduction in mean pain scores was modest.

Pain scores at one to three months after intervention for other (non-median) nerve compression/trauma trials

(Table 3, Fig. 4)

A meta-analysis of the data from the three trials involving patients with other than median nerve pathology $25,27,28$ showed that there was no significant difference in mean pain scores between the steroid and the LA/CMM groups $(-1.64$ points; $95 \% \mathrm{CI}$ : -3.52 to $0.24 ; P=0.09 ; I^{2}=92 \%$ ).

Secondary outcomes

None of the studies reported planned secondary outcomes of anxiety, depression, quality of life, and overall patient satisfaction, although adverse effects were reported in two
Table 2 Reduction in mean pain scores from baseline (preintervention) to one to three months in individual studies

\begin{tabular}{llll}
\hline Study ID & $\begin{array}{l}\text { Pain score measurement: } \\
\text { time after intervention }\end{array}$ & $\begin{array}{l}\text { Reduction in mean pain } \\
\text { score from baseline } \\
\text { Steroids LA }\end{array}$ \\
\hline Eker 2012 & 3 months & $75 \%$ & $35.5 \%$ \\
Karadas $2012^{26}$ & 2 months & $31.8 \%$ & $20.2 \%$ \\
Thomson $2013^{27}$ & 1 month & $38 \%$ & $28 \%$ \\
Singh 2013 & 3 months & $60 \%$ & $50 \%$ \\
Karadas $2011^{29}$ & 2 months & $29 \%$ & $16 \%$ \\
\hline
\end{tabular}

$\mathrm{LA}=$ local anesthetic

studies. Singh et al. reported only procedure-related (not medication-related) complications in the group that received perineural steroid injections (the other group did not receive injections). All of their reported complications were related to an inadvertent blockade of nerves in the vicinity of the ninth cranial nerve and included hoarseness of voice (four of 15 patients) and difficulty in swallowing (two of 15 patients). ${ }^{28}$ Thomson et al. reported hypopigmentation of the dorsal skin over the injection site and atrophy of the plantar fat pad in 5\% (three of 64 patients) and 3\% (two of 64 patients), respectively, of the patients who received steroids. $^{27}$

Heterogeneity and publication bias

For the primary outcomes, the $I^{2}$ statistic was $89 \%$ for the comparison of mean post-intervention pain scores, indicating high heterogeneity. Several characteristics of these studies can contribute to heterogeneity, and we explored two of these by subgroup analysis (Table 3). The characteristics we evaluated included the interval between

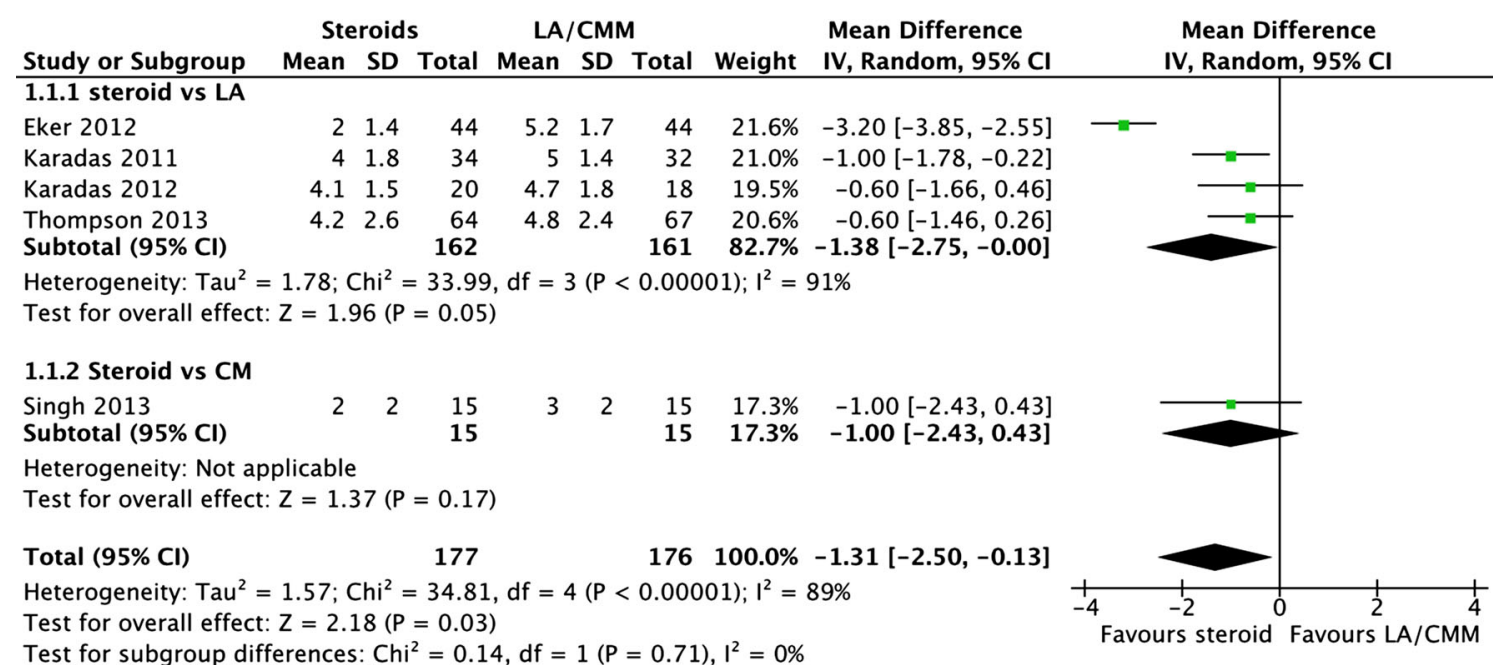

Fig. 3 Forest plot for numerical rating scale pain scores at one to three months after perineural injections. Pooled data analysis: steroids $v s$ local anesthetics (LA) or conventional medical management (CMM). CI = confidence interval 
Table 3 Subgroup analyses

\begin{tabular}{|c|c|c|c|c|c|c|}
\hline Category & Subgroups & $\begin{array}{l}\text { Number of } \\
\text { studies }\end{array}$ & $\begin{array}{l}\text { Number of } \\
\text { participants }\end{array}$ & $\begin{array}{l}\text { Mean difference in } \\
\text { pain scores at } \\
1-3 \text { months }(95 \% \mathrm{CI})^{*}\end{array}$ & $P$ value & $I^{2}(\%)$ \\
\hline \multirow[t]{2}{*}{ Type of nerve } & Median nerve $\mathrm{e}^{26,29}$ & 2 & 104 & $-0.86(-1.49$ to -0.23$)$ & 0.007 & 0 \\
\hline & Other nerves ${ }^{25,27,28}$ & 3 & 249 & $-1.64(-3.52$ to 0.24$)$ & 0.09 & 92 \\
\hline \multirow{2}{*}{$\begin{array}{l}\text { Time after intervention } \\
\text { for assessing efficacy }\end{array}$} & Early (1-2 months $)^{26,27,29}$ & 3 & 235 & $-0.77(-1.28$ to -0.26$)$ & 0.003 & 0 \\
\hline & Late (3 months) $)^{25,28}$ & 2 & 118 & $-2.20(-4.34$ to -0.05$)$ & 0.05 & 87 \\
\hline \multirow[t]{2}{*}{ Risk of bias } & Low $^{25,27}$ & 2 & 219 & $-1.92(-4.46$ to 0.63$)$ & 0.14 & 96 \\
\hline & $\operatorname{High}^{26,28,29}$ & 3 & 134 & $-0.88(-1.46$ to -0.31$)$ & 0.003 & 0 \\
\hline
\end{tabular}

*A negative value of the mean difference in pain scores indicates that pain scores for steroids were lower than scores for local anesthetics or conventional medical management. $\mathrm{CI}=$ confidence interval

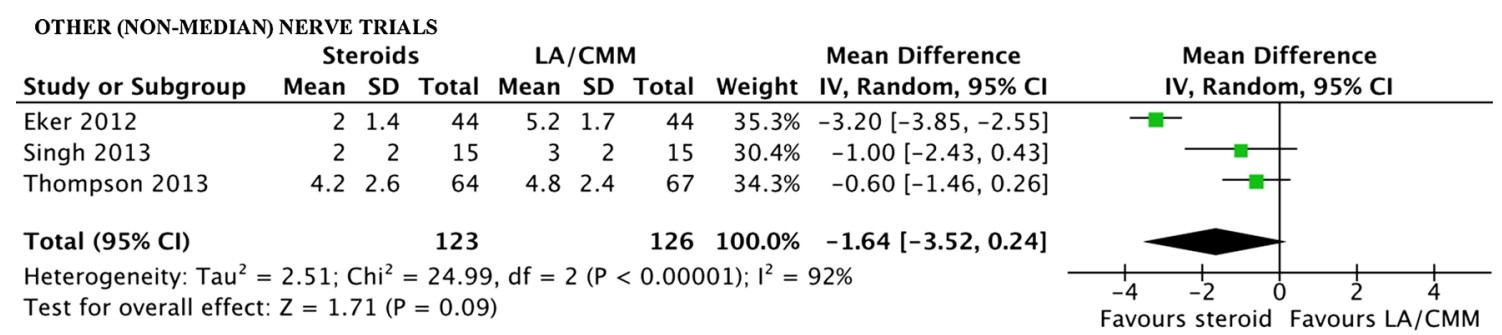

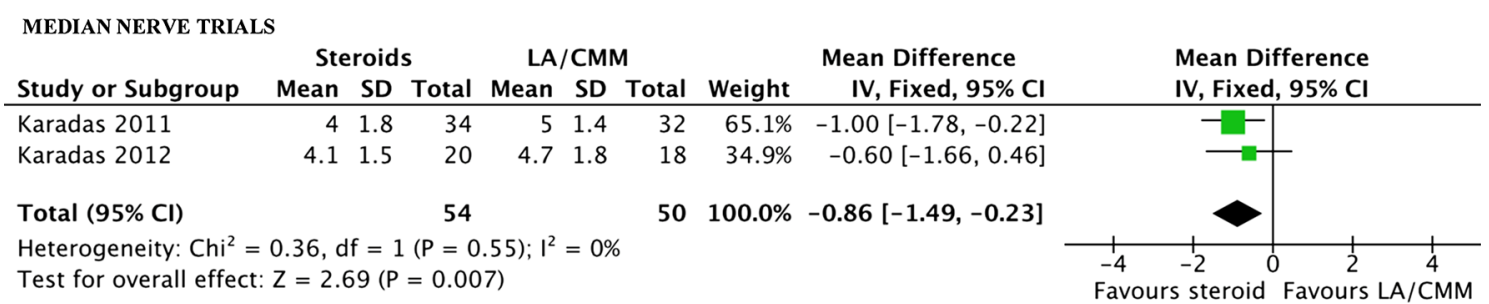

Fig. 4 Forest plot for numerical rating scale pain scores at one to three months after perineural injections. Pooled data analysis from subgroups: other (non-median) nerve compression and median nerve

intervention and assessment of outcome (early vs late) (Fig. 5) and risk of bias in the included studies (low vs high) (Fig. 6).

\section{Early vs late measurement of post-intervention pain scores (Table 3, Fig. 5)}

There was a significant difference in the mean pain scores in the steroid vs LA groups when these were measured relatively early, at one to two months after the interventions. $^{26,27,29}$ Steroids were more efficacious in reducing pain than $\mathrm{LA}$ at this time point $(-0.77$ points; $95 \% \mathrm{CI}:-1.28$ to $\left.-0.26 ; P=0.003 ; I^{2}=0 \%\right)$. The result was similar when pain scores were measured later, at three months after the intervention, ${ }^{25,28}$ but the reduction in pain scores was greater with steroids $(-2.20$ points; $95 \% \mathrm{CI}$ : -4.34 to $\left.-0.05 ; \quad P=0.05 ; \quad I^{2}=87 \%\right)$, though the compression/trauma trials - steroids vs local anesthetics (LA) or conventional medical management $(\mathrm{CMM}) . \mathrm{CI}=$ confidence interval

confidence intervals were wider and the statistical significance was borderline.

Low risk of bias vs high risk of bias RCTs (Table 3, Fig. 6)

The pooled post-intervention mean pain scores did not show a significant difference between steroids and LA when these were extracted from studies with only low risk of bias $(-1.92$ points; $95 \% \mathrm{CI}$ : -4.46 to $0.63 ; P=0.14$; $\left.I^{2}=96 \%\right) .^{25,27}$ Nevertheless, pooled data from studies with a high risk of bias showed a significant difference ( -0.88 points; $95 \% \mathrm{CI}:-1.46$ to $-0.31 ; P=0.003$; $\left.I^{2}=0 \%\right)^{26,28,29}$

Publication bias was not assessed with a funnel plot because the low number of eligible studies (less than ten) decreases the power of the tests to distinguish chance from real asymmetry. ${ }^{30}$ 


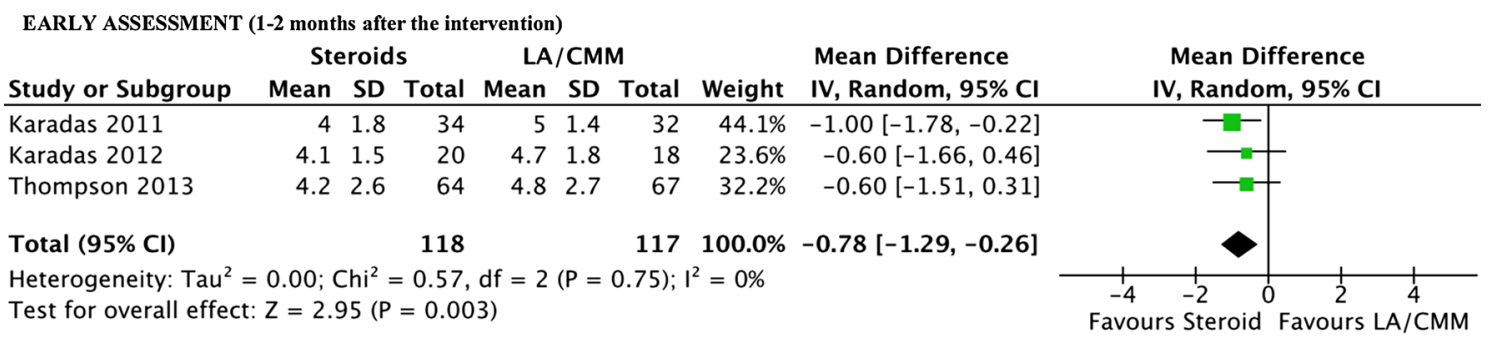

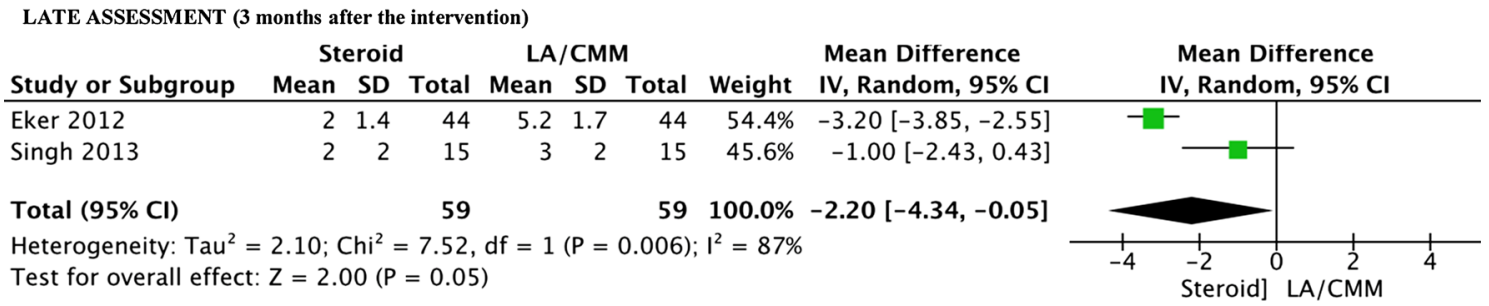

Fig. 5 Forest plots for numerical rating scale pain scores measured early (at one to two months) and late (at three months) after perineural injections. Pooled data analysis from subgroups: early assessment and late assessment of outcome trials - steroids $v s$ local anesthetics (LA) or conventional medical management $(\mathrm{CMM}) . \mathrm{CI}=$ confidence interval

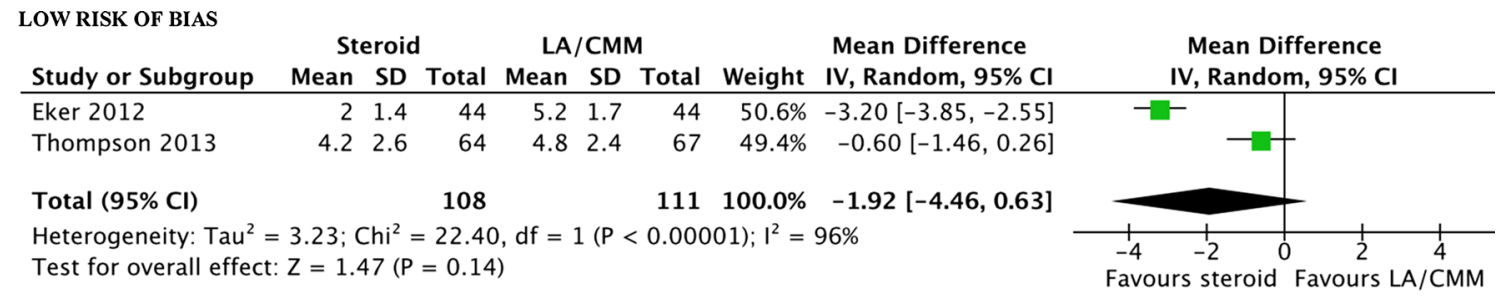

HIGH RISK OF BIAS

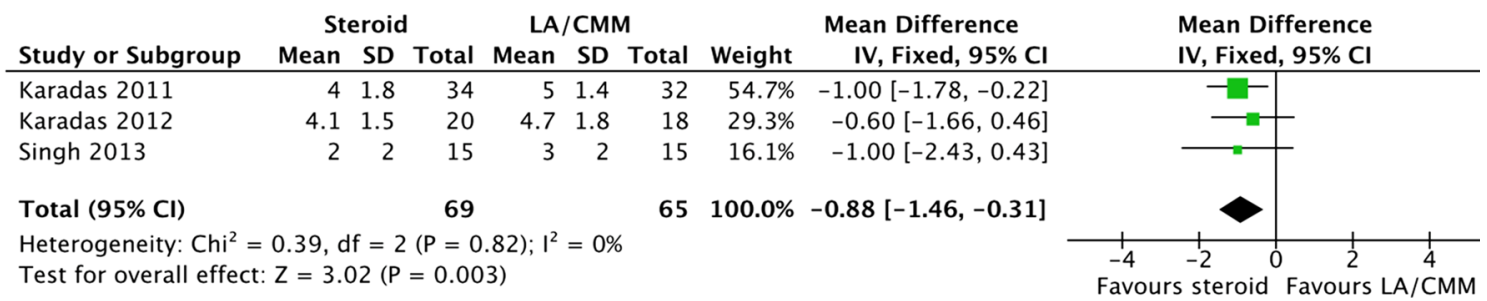

Fig. 6 Forest plots for numerical rating scale pain scores from low risk $v s$ high risk of bias studies. Pooled data analysis from subgroups: low risk of bias and high risk of bias trials - steroids $v s$ local anesthetics (LA) or conventional medical management $(\mathrm{CMM})$. CI $=$ confidence interval

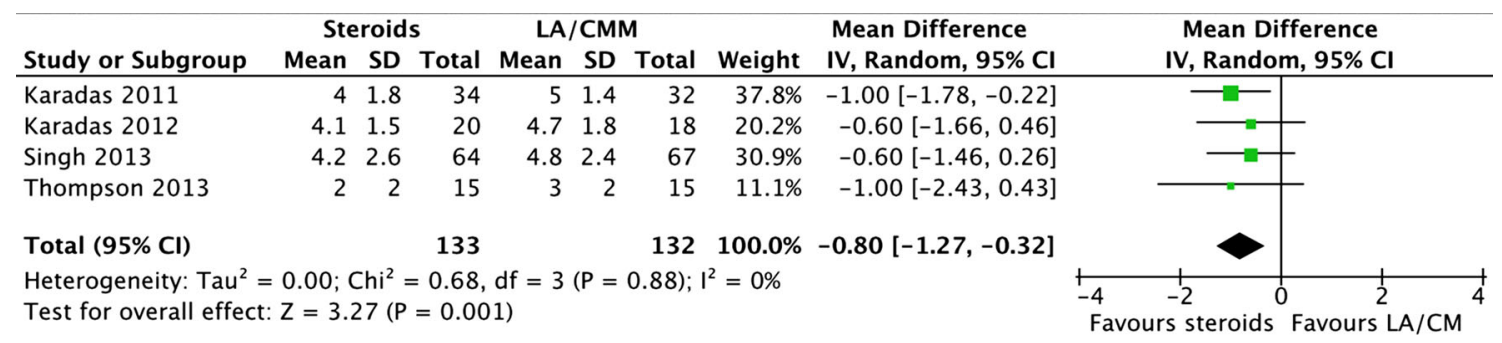

Fig. 7 Sensitivity analysis: Forest plot for numerical rating scale pain scores at one to three months after perineural injections after excluding data from trial by Eker et al. ${ }^{18}$ Pooled data analysis of the mean change in pain scores: steroids $v s$ local anesthetics (LA) or conventional medical management $(\mathrm{CMM}) . \mathrm{CI}=$ confidence interval 


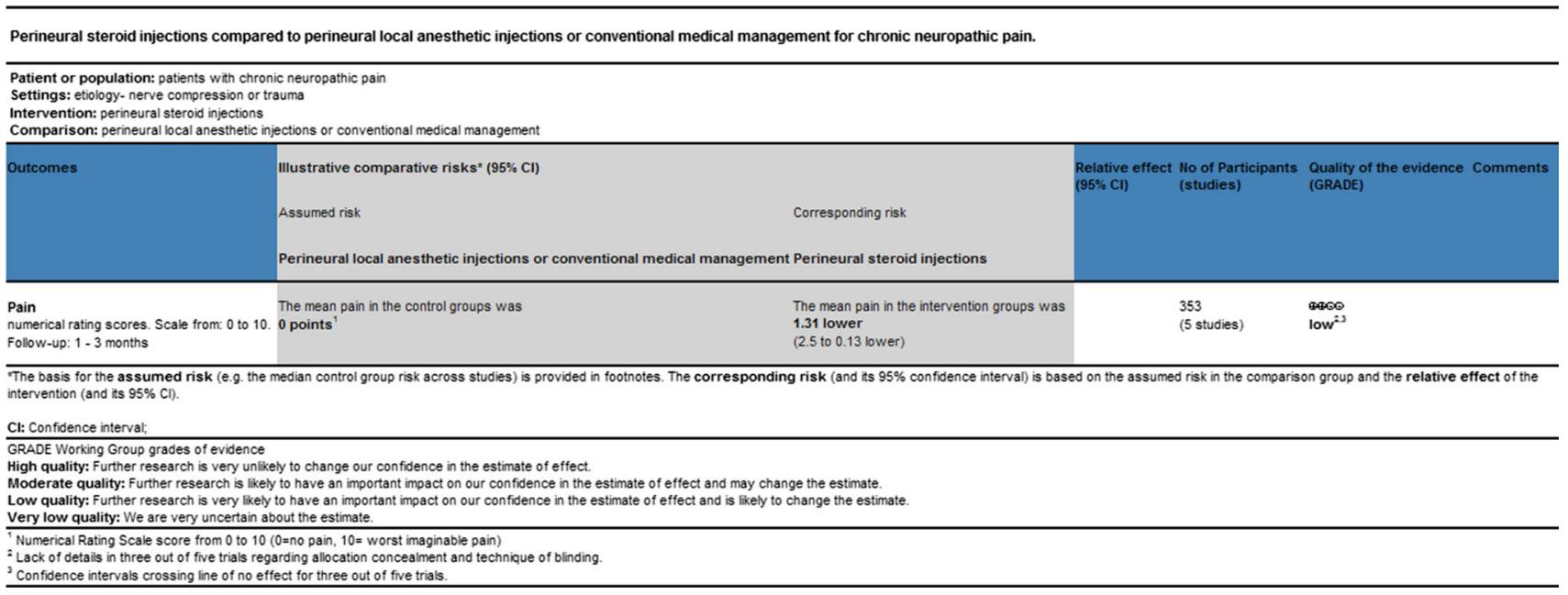

Fig. 8 Summary of findings table based on GRADE evidence evaluation

Sensitivity analysis

A sensitivity analysis was not planned a priori, but it was performed after removing the study by Eker et al. ${ }^{25}$ because their study results were strongly in favour of perineural steroids. Though removing this study resulted in a decrease in the pooled effect size $(-0.80$ points; $95 \% \mathrm{CI}:-1.27$ to $-0.32 ; P=0.001 ; I^{2}=0 \%$ ), the overall pooled effect was still significant and heterogeneity was reduced (Fig. 7).

Based on a high risk of bias in three of the five studies, the quality of evidence was classified as low, and thus, the strength of recommendation is weak for the analgesic efficacy of perineural steroids in trauma or compressionrelated NP (Fig. 8).

\section{Discussion}

This systematic review and meta-analysis evaluated the efficacy of using perineural steroids for relieving chronic peripheral post-traumatic or compression-related NP. Results show that 40-80 mg of methylprednisolone or triamcinolone (these steroids are equipotent) ${ }^{31}$ have a potentially beneficial effect in reducing pain at one to three months after injection when compared with LA injection or CMM (i.e., no injections). The change in mean pain scores following injection of steroids represented a modest change from baseline $(25 \%)$ but a significant reduction $(P=0.03)$. The quality of evidence is low and the strength of recommendation is weak for analgesic efficacy of perineural steroids in this clinical setting. The number of subjects included in the RCTs was small. Moreover, these studies did not report on secondary outcomes relevant to chronic pain (anxiety, depression, quality of life, and patient satisfaction) and the adverse effects of the interventions.
Population included in this review

A wide spectrum of peripheral NP syndromes of traumatic or compressive etiologies was included in the studies included in this review. Furthermore, the majority of the trials did not include validated scales for the diagnosis of NP. Both of these factors contributed to the heterogeneity of our review. The analgesic benefit of steroids was apparent in patients suffering from median nerve compression; however, the number of studies assessing efficacy in this subgroup was even smaller. This suggests that the efficacy of steroids may differ based on the type of nerve involved or the pathology.

To enhance the validity of our results, we attempted to restrict our inclusion criteria to studies that involved perineural administration of injectate with nerve localization (anatomic landmarks, stimulation, or ultrasound). For example, we excluded a study that involved injecting steroids in the suboccipital region for the treatment of chronic headaches in the absence of occipital neuralgia. ${ }^{32}$ In all the included studies, patients had pain scores of $>3$ (on a 0-10 NRS) for more than three months, thus confirming that they had chronic pain of moderate intensity or higher.

Analgesic efficacy of steroids in chronic peripheral NP

Corticosteroids have anti-inflammatory mechanisms and immunosuppressant actions. Nerve injury has been shown to activate secretion of inflammatory mediators and increase ectopic discharge from the injured nerve, ${ }^{4}$ thereby contributing to the development of NP. ${ }^{12,13}$ Steroids delivered around injured nerve fibres counter both mechanisms, ${ }^{14}$ which results in a reduction of both spontaneous and evoked pain. Perineurally injected 
steroids may also have some analgesic effect through systemic uptake. Our results represent an analgesic benefit of $25 \%$, which is an important finding and a meaningful reduction in pain, considering that most patients in these trials had failed to respond to pharmacological treatments for NP. We also observed a larger reduction in pain scores in trials that involved the use of higher doses of steroids (methylprednisolone $80 \mathrm{mg}$ ) and recorded pain scores at three months ${ }^{25,28}$ when compared with trials that used lower doses of steroids (methylprednisolone or triamcinolone $40 \mathrm{mg}$ ) and recorded pain scores relatively earlier (at one to two months). ${ }^{26,27,29}$ This finding is unusual because the analgesic benefit should dissipate over time, but it is possible that higher doses may confer longterm analgesia. This temporal pattern of analgesia should be explored in future RCTs with assessment at different time points after administration of steroids.

We found that studies with a high risk of bias $26,28,29$ were associated with a significant analgesic effect in favour of perineural steroids. It can be argued that it is premature to do a meta-analysis on this topic, especially considering the lack of quality studies. Nevertheless, the evidence of an analgesic benefit conferred by perineural steroids in patients with refractory NP can serve as a "launch-pad" for better designed clinical trials in more homogeneous models of NP.

\section{Limitations of this review}

Despite not restricting our literature search by date of publication, all five studies included in this review were published from 2011-2013. This suggests that this topic has been subject to clinical research only recently and larger and more robust RCTs can be expected in the next few years. Interestingly, all included trials showed a beneficial effect of steroids when compared with LA in a population of patients (chronic NP) in which providing pain relief can be challenging and the number needed to treat for all recommended oral pharmacological agents varies from 2.5- 4.5

A limitation of this review is that data from studies reporting one or more of the secondary outcome measures (but not the primary outcome measure) were not included for analysis. This may have resulted in the omission of significant studies on the effects of perineural steroids on trauma or compression-related peripheral NP, but we consider this unlikely because of the paucity of reporting on secondary non-analgesic outcomes in trials evaluating interventional modalities for chronic pain. ${ }^{33}$ It should also be pointed out that studies conducted and published in languages other than English were not included in our search due to the paucity of data on the validation of scales for the diagnosis, measurement, and evaluation of NP in languages other than English. Nevertheless, this may not have significantly affected the pooled estimate of our primary outcome. ${ }^{34}$ A neuropathic pain diagnostic questionnaire (DN4, Douleur Neuropathique en 4 Questions) has recently been validated in multiple languages, ${ }^{35}$ and more highquality studies on the effect of perineural steroids on peripheral NP can be expected in the future.

The RCTs included in this review had heterogeneity and variable quality. There was clinical heterogeneity due to different etiologies and different nerves responsible for NP. The comparators also varied in types, concentrations, and dose across RCTs, and one trial did not have injections in the comparator group. ${ }^{28}$ The RCTs included in this metaanalysis did not outline other multimodal therapies used for patients (e.g., antidepressants, physical or psychological therapy). None of the RCTs reported on the other important "core" outcomes of anxiety and depression, quality of life, or satisfaction with treatment. Finally, the primary outcome was measured at a range of intervals after the intervention. Nevertheless, we decided that these differences in methodology should not have a major impact on the confidence in the results of this meta-analysis.

There was clinical and statistical heterogeneity in the results of the included RCTs. The trials enrolled patients with neuropathic syndromes secondary to trauma or compression of different nerves. The pathology of neural dysfunction following a variety of insults includes swelling of the nerve and ectopic discharges. ${ }^{9}$ Given that these abnormalities in neural anatomy and function are amenable to the anti-inflammatory and membrane stabilizing effects of steroids, we considered it reasonable to combine these seemingly disparate papers for this meta-analysis in order to evaluate the analgesic benefit of perineural steroids. Moreover, sensitivity analyses of trials with lower heterogeneity (median nerve compression) ${ }^{26,29}$ revealed no significant decrease in the analgesic benefit conferred by perineural steroids (Table 3). Similarly, exclusion of the RCT with the highest treatment effect ${ }^{25}$ did not remove the significance of the pooled effect, though the magnitude decreased (Fig. 7). We observed a lack of benefit with perineural steroids when data from RCTs with only a low risk of bias was analyzed (Table 3, Fig. 6). Nevertheless, since only two RCTs met this criterion, we do not consider this sensitivity analysis to negate the results of our metaanalysis of all five RCTs. A prominent focus on study bias and quality of evidence was maintained throughout the analysis using GRADE. ${ }^{24}$

Future randomized controlled trials conducted with larger enrolment may be able to define the analgesic benefit of perineural steroids with more clarity and confidence. Despite steroids being associated with multiple local and systemic effects, adverse effects were not clearly stated as an outcome in any of the studies included in this review. ${ }^{36}$ Only one trial in this review 
reported local adverse effects of perineural steroids. ${ }^{27}$ Randomized controlled trials that evaluate perineural injections of steroids should include monitoring of welldefined adverse effects. Hyperglycemia and osteoporosis are two effects that could be relatively easy to identify at multiple time points after intervention. Fluid retention, hypertension, skin necrosis, myopathy, hypokalemia, and psychosis are other adverse effects of steroids that need to be assessed.

Implications for clinical practice and research

Administration of perineural steroids may help to ameliorate chronic peripheral NP, but the benefit and risk profile is unclear. It is important to perform large multicentre RCTs that evaluate the efficacy of this intervention in a range of trauma or compression/ entrapment-related chronic neuropathic syndromes that cause pain of moderate-to-severe intensity. Diagnosis of NP should be confirmed through use of validated measures (e.g., DN4, LANSS). In view of some evidence, namely, that combining steroids with LA may increase efficacy, ${ }^{26}$ that LA on their own may confer long-term analgesic benefits, ${ }^{37}$ and that placebo analgesic effect is strong, ${ }^{38}$ there is a need to perform an RCT with four groups of perineural injectates: no/sham injection, LA, steroid, and a combination of steroid with LA, respectively. The sample size for this trial should be at least 33 patients per group (132 patients in total) for an expected mean difference between pain NRS of 1.8 and a within-group standard deviation of 2 . This sample size is expected to give an $80 \%$ chance of rejecting the null hypothesis of no difference between means at an alpha of 0.05 using a Bonferroni adjustment to the size of the test to compensate for multiple comparisons. ${ }^{39}$ Pain scores should be measured at multiple time intervals after intervention: immediate (0-72 hr), intermediate ( $72 \mathrm{hr}$ to one month), and long-term (one to six months). Important secondary outcome measurements to include in this trial are: emotional functioning, physical functioning, patient satisfaction with treatment, as well as meticulous attempts to identify and record adverse effects. These recommendations are in accordance with the core outcome domains of the IMMPACT guidelines for designing clinical trials to evaluate interventions for chronic pain conditions. ${ }^{33}$

\section{Conclusions}

Perineural steroids may provide higher analgesic efficacy than LAs or CMM for treating chronic peripheral NP from traumatic or compressive etiologies; however, more welldesigned studies are required.
Acknowledgements We thank Ms. Marina Englesakis, Librarian, University Health Network, Toronto for her help in searching the literature.

Funding This research project was funded by internal funding from the Department of Anesthesia and Pain Management of the University Health Network - Toronto Western Hospital.

Conflicts of interest None declared.

\section{References}

1. Bouhassira D, Lantéri-Minet $M$, Attal $N$, Laurent B, Touboul C. Prevalence of chronic pain with neuropathic characteristics in the general population. Pain 2008; 136: 380-7.

2. Treede RD, Jensen TS, Campbell JN, et al. Neuropathic pain: redefinition and a grading system for clinical and research purposes. Neurology 2008; 70: 1630-5.

3. Haanpaa $M$, Treede $R D$. Diagnosis and classification of neuropathic pain. Pain Clinical Updates 2010; XVIII: 7.

4. Moalem $G$, Tracey DJ. Immune and inflammatory mechanisms in neuropathic pain. Brain Res Rev 2006; 51: 240-64.

5. Harden RN. Chronic neuropathic pain. Mechanisms, diagnosis, and treatment. Neurologist 2005; 11: 111-22.

6. Turk DC. Clinical effectiveness and cost-effectiveness of treatments for patients with chronic pain. Clin J Pain 2002; 18 : 355-65.

7. Attal N, Lanteri-Minet M, Laurent B, Fermanian J, Bouhassira D. The specific disease burden of neuropathic pain: results of a French nationwide survey. Pain 2011; 152: 2836-43.

8. Kehlet H, Jensen TS, Woolf CJ. Persistent postsurgical pain: risk factors and prevention. Lancet 2006; 367: 1618-25.

9. Zimmermann M. Pathobiology of neuropathic pain. Eur J Pharmacol 2001; 429: 23-37.

10. Chin KJ, Wong NW, Macfarlane AJ, Chan VW. Ultrasoundguided versus anatomic landmark-guided ankle blocks: a 6-year retrospective review. Reg Anesth Pain Med 2011; 36: 611-8.

11. Van Zundert J, Hartrick C, Patijn J, Huygen F, Mekhail N, van Kleef $M$. Evidence-based interventional pain medicine according to clinical diagnoses. Pain Pract 2011; 11: 423-9.

12. Sommer $C$, Kress $M$. Recent findings on how proinflammatory cytokines cause pain: peripheral mechanisms in inflammatory and neuropathic hyperalgesia. Neurosci Lett 2004; 361: 184-7.

13. Zhang JM, An J. Cytokines, inflammation, and pain. Int Anesthesiol Clin 2007; 45: 27-37.

14. Johansson A, Bennett GJ. Effect of local methylprednisolone on pain in a nerve injury model. A pilot study. Reg Anesth 1997; 22: 59-65.

15. Markovic M, Crichton $K$, Read JW, Lam P, Slater HK. Effectiveness of ultrasound-guided corticosteroid injection in the treatment of Morton's neuroma. Foot Ankle Int 2008; 29: 483-7.

16. Wang JC, Chiou HJ, Lu JH, Hsu YC, Chan RC, Yang TF. Ultrasound-guided perineural steroid injection to treat intractable pain due to sciatic nerve injury. Can J Anesth 2013; 60: 902-6.

17. Johansson A, Sjolund B. Nerve blocks with local anesthetics and corticosteroids in chronic pain: a clinical follow-up study. J Pain Symptom Manage 1996; 11: 181-7.

18. Higgins JP, Green S. Guide to the contents of a Cochrane protocol and review. In: Higgins JP, Green S (Eds). Cochrane Handbook for Systematic Reviews of Interventions, Version 5.1.0. The Cochrane Collaboration - 2011. Available from URL: http://handbook.cochrane.org/chapter_4/4_guide_to_the_contents_ 
of_a_cochrane_protocol_and_review.htm (accessed January 2015).

19. Liberati A, Altman DG, Tetzlaff $J$, et al. The PRISMA statement for reporting systematic reviews and meta-analyses of studies that evaluate healthcare interventions: explanation and elaboration. BMJ 2009; 339: b2700.

20. Lefebvre C, Manheimer E, Glanville J. Searching for studies. In: Higgins JP, Green S, (Eds). Cochrane Handbook for Systematic Reviews of Interventions, Chapter 6.4 - Version 5.0.1. - 2008. The Cochrane Collaboration. Available from URL: http://www. cochrane.org/handbook (accessed January 2015).

21. Higgins JP, White IR, Wood AM. Imputation methods for missing outcome data in meta-analysis of clinical trials. Clin Trials 2008; 5: 225-39.

22. DerSimonian R, Laird N. Meta-analysis in clinical trials. Control Clin Trials 1986; 7: 177-88.

23. Sonohata M, Tsuruta T, Mine $H$, et al. Clinical characteristics of neuropathic pain in patients with carpal tunnel syndrome. Hand Surg 2014; 19: 43-8.

24. Guyatt G, Oxman AD, Akl EA, et al. GRADE guidelines: 1. Introduction-GRADE evidence profiles and summary of findings tables. J Clin Epidemiol 2011; 64: 383-94.

25. Eker HE, Cok OY, Aribogan A, Arslan G. Management of neuropathic pain with methylprednisolone at the site of nerve injury. Pain Med 2012; 13: 443-51.

26. Karadas $O$, Tok $F$, Akarsu $S$, Tekin L, Balaban B. Triamcinolone acetonide vs procaine hydrochloride injection in the management of carpal tunnel syndrome: randomized placebo-controlled study. J Rehabil Med 2012; 44: 601-4.

27. Thomson CE, Beggs I, Martin DJ, et al. Methylprednisolone injections for the treatment of Morton neuroma: a patient-blinded randomized trial. J Bone Joint Surg Am 2013; 95: 790-8.

28. Singh PM, Dehran M, Mohan VK, Trikha A, Kaur M. Analgesic efficacy and safety of medical therapy alone vs combined medical therapy and extraoral glossopharyngeal nerve block in glossopharyngeal neuralgia. Pain Med 2013; 14: 93-102.

29. Karadas $O$, Tok F, Ulaş UH, Odabasi $Z$. The effectiveness of triamcinolone acetonide vs. procaine hydrochloride injection in the management of carpal tunnel syndrome: a double-blind randomized clinical trial. Am J Phys Med Rehabil 2011; 90: 28792.

30. Sterne JA, Egger M, Moher D; Cochrane Bias Methods Group. Addressing reporting biases. In: Higgins JP, Green S (Eds). Cochrane Handbook for Systematic Reviews of Interventions, Chapter 10 - Version 5.1.0 - 2011. The Cochrane Collaboration. Available from URL: http://www.cochrane.org/sites/default/files/ Handbook510pdf_Ch10_ReportingBias.pdf (accessed January 2015).

31. Lennard TA, Walkowski SA, Singla AK, Vivian D. Pain Procedures in Clinical Practice. 3rd ed. Philadelphia, PA: Elsevier Saunders; 2011.

32. Ambrosini A, Vandenheede $M$, Rossi $P$, et al. Suboccipital injection with a mixture of rapid- and long-acting steroids in cluster headache: a double-blind placebo-controlled study. Pain 2005; 118: 92-6.

33. Dworkin R, Turk DC, Farrar JT, et al. Core outcome measures for chronic pain clinical trials: IMMPACT recommendations. Pain 2005; 113: 9-19.

34. Morrison A, Polisena J, Husereau D, et al. The effect of Englishlanguage restriction on systematic review-based meta-analyses: a systematic review of empirical studies. Int $\mathbf{J}$ Technol Assess Health Care 2012; 28: 138-44.

35. Van Seventer $R$, Vos C, Meerding $W$, et al. Linguistic validation of the DN4 for use in international studies. Eur J Pain 2010; 14: 58-63.

36. Habib GS. Systemic effects of intra-articular corticosteroids. Clin Rheumatol 2009; 28: 749-56.

37. Andreae $M H$, Andreae DA. Local anaesthetics and regional anaesthesia for preventing chronic pain after surgery. Cochrane Database Syst Rev 2012; 10: CD007105.

38. Farrar JT, Young JP Jr, LaMoreaux L, Werth JL, Poole RM. Clinical importance of changes in chronic pain intensity measured on an 11-point numerical pain rating scale. Pain 2001; 94: 149-58.

39. Dallal GE. Sample Size Calculations Simplified - 1997. Available from URL: http://www.jerrydallal.com/LHSP/SIZE. HTM (accessed January 2015). 